\title{
Unil
}

UNIL | Université de Lausanne

Unicentre

$\mathrm{CH}-1015$ Lausanne

http://serval.unil.ch

Year : 2018

\section{Impact of total ischemic time on manual thrombus aspiration benefit during primary percutaneous coronary intervention}

\author{
Hugelshofer Sarah
}

Hugelshofer Sarah, 2018, Impact of total ischemic time on manual thrombus aspiration benefit during primary percutaneous coronary intervention

Originally published at : Thesis, University of Lausanne

Posted at the University of Lausanne Open Archive http://serval.unil.ch

Document URN : urn:nbn:ch:serval-BIB_C1FE845B4A3A8

\section{Droits d'auteur}

L'Université de Lausanne attire expressément l'attention des utilisateurs sur le fait que tous les documents publiés dans l'Archive SERVAL sont protégés par le droit d'auteur, conformément à la loi fédérale sur le droit d'auteur et les droits voisins (LDA). A ce titre, il est indispensable d'obtenir le consentement préalable de l'auteur et/ou de l'éditeur avant toute utilisation d'une oeuvre ou d'une partie d'une oeuvre ne relevant pas d'une utilisation à des fins personnelles au sens de la LDA (art. 19, al. 1 lettre a). A défaut, tout contrevenant s'expose aux sanctions prévues par cette loi. Nous déclinons toute responsabilité en la matière.

\section{Copyright}

The University of Lausanne expressly draws the attention of users to the fact that all documents published in the SERVAL Archive are protected by copyright in accordance with federal law on copyright and similar rights (LDA). Accordingly it is indispensable to obtain prior consent from the author and/or publisher before any use of a work or part of a work for purposes other than personal use within the meaning of LDA (art. 19, para. 1 letter a). Failure to do so will expose offenders to the sanctions laid down by this law. We accept no liability in this respect. 


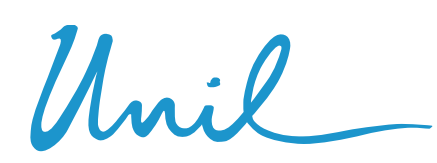

UNIL | Université de Lausanne

\title{
Ecole doctorale
}

\author{
UNIVERSITE DE LAUSANNE - FACULTE DE BIOLOGIE ET DE MEDECINE \\ Département cœur-vaisseaux, CHUV \\ Service de cardiologie
}

\section{Impact of total ischemic time on manual thrombus aspiration benefit during primary percutaneous coronary intervention}

\section{THESE}

préparée sous la direction du Professeur Olivier Muller

(et la co-direction du Docteur Juan F. Iglesias)

et présentée à la Faculté de biologie et de médecine de l'Université de Lausanne pour l'obtention du grade de

DOCTEUR EN MEDECINE

$$
\text { Par }
$$

\section{Sarah HUGELSHOFER}

Médecin diplômée de la Confédération Suisse

Originaire de Frauenfeld (Thurgovie) 


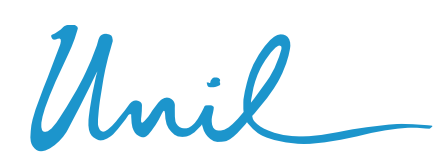

UNIL | Université de Lausanne

\title{
Ecole doctorale
}

\author{
UNIVERSITE DE LAUSANNE - FACULTE DE BIOLOGIE ET DE MEDECINE \\ Département cœur-vaisseaux, CHUV \\ Service de cardiologie
}

\section{Impact of total ischemic time on manual thrombus aspiration benefit during primary percutaneous coronary intervention}

\section{THESE}

préparée sous la direction du Professeur Olivier Muller

(et la co-direction du Docteur Juan F. Iglesias)

et présentée à la Faculté de biologie et de médecine de l'Université de Lausanne pour l'obtention du grade de

DOCTEUR EN MEDECINE

$$
\text { Par }
$$

\section{Sarah HUGELSHOFER}

Médecin diplômée de la Confédération Suisse

Originaire de Frauenfeld (Thurgovie) 


\section{Imprimatur}

Vu le rapport présenté par le jury d'examen, composé de

Directeur de thèse Monsieur le Docteur Olivier Muller

Co-Directeur de thèse Monsieur le Docteur Juan F. Iglesias

Expert

Monsieur le Professeur Gérard Waeber

Vice-Directeur de

Monsieur le Professeur John Prior

l'Ecole doctorale

la Commission MD de l'Ecole doctorale autorise l'impression de la thèse de

\section{Madame Sarah HUGELSHOFER}

intitulée

Impact of total ischemic time on manual thrombus aspiration benefit during primary percutaneous coronary intervention

Lausanne, le 20 septembre 2018

pour Le Doyen

de la Faculté de Biologie et de Médecine

Monsieur le Professeur John Prior

Vice-Directeur de l'Ecole doctorale 


\section{Résumé de la thèse: Impact of total ischemic time on manual thrombus aspiration benefit during primary percutaneous coronary intervention, American Heart Journal, manuscript accepted May 30, 2018.}

\section{Importance du sujet}

L'infarctus myocardique aigu est une pathologie fréquente avec chaque année en Suisse 15'000 évènements recensés et constitue la cause directe de $40 \%$ de décès chez les personnes âgées de plus de 65 ans. Une reperfusion coronarienne rapide est primordiale surtout s'il s'agit d'une occlusion artérielle thrombotique se manifestant par un sus-décalage du segment ST à l'ECG (en anglais : ST-segment elevation myocardial infarction, ou STEMI). Le 'gold standard' étant une revascularisation percutanée, il reste débattu si l'aspiration manuelle du thrombus pendant cette intervention est bénéfique.

\section{Objectif}

Effectuer une étude rétrospective de patients inclus dans un large registre national (Acute Myocardial Infarction in Switzerland Plus, ou AMIS Plus) en comparant le traitement par revascularisation percutanée avec versus sans thromboaspiration.

\section{Méthodes}

Une analyse multivariée a été conduite chez des patients avec STEMI traités par revascularisation percutanée en comparant le groupe avec thromboaspiration et le groupe sans thromboaspiration. Les résultats ont été ajustés par rapport à l'âge, le sexe, la présence de diabète, hypertension artérielle, insuffisance rénale chronique, choc cardiogénique, infarctus antérieur et d'une maladie coronarienne pluri-tronculaire. Pour des analyses supplémentaires les patients ont été stratifiés selon la durée de leurs symptômes jusqu'à l'intervention, en temps d'ischémie court ( $<3$ heures), moyen (3-6 heures) et long ( $>6$ heures). Le critère principal (endpoint primaire) est la mortalité intra-hospitalière de toute cause et le critère secondaire (endpoint secondaire) les évènements cardio-vasculaires majeurs soit un nouvel infarctus myocardique, un accident cérébro-vasculaire ischémique, ou le décès (en anglais : Major Adverse Cardiovascular Event, ou MACE).

\section{Résultats}

Entre 2008 et 2014, 4154 patients avec STEMI ont été inclus et presque la moitié (48\%) traitée par thromboaspiration. Après une analyse multivariée la mortalité intrahospitalière de toutes causes confondues n'est pas significativement différente entre les deux groupes (OR 1.29; 95\%CI 0.83-1.98; $\mathrm{p}=0.26$ ) mais le groupe de patients avec thromboaspiration présente plus de MACE (OR 1.52 ; 95\%CI 1.05-2.19; p=0.03).

\section{Conclusions}

Dans un large registre national de patients avec STEMI la thromboaspiration manuelle n'est pas associée à une diminution du risque de décès intra-hospitalier indépendamment du temps d'ischémie, mais au contraire semble aboutir à une augmentation du risque d'évènements cardiovasculaires majeurs. L'augmentation du risque de MACE est notamment significative chez des patients avec une longue durée d'ischémie. 


\section{Impact of total ischemic time on manual thrombus aspiration benefit during primary percutaneous coronary intervention}

Sarah Hugelshofer, MD, ${ }^{\mathrm{a}}$ Marco Roffi, MD, ${ }^{\mathrm{b}}$ Fabienne Witassek, MS, ${ }^{\mathrm{c}}$ Franz R. Eberli, MD, ${ }^{\mathrm{d}}$ Thomas Pilgrim, MD, ${ }^{\mathrm{e}}$ Giovanni Pedrazzini, MD, ${ }^{\mathrm{f}}$ Hans Rickli, MD, ${ }^{\mathrm{g}}$ Dragana Radovanovic, MD, ${ }^{\mathrm{c}}$ Paul Erne, $\mathrm{MD},{ }^{\mathrm{h}}$ Sophie Degrauwe, $\mathrm{MD},{ }^{\mathrm{b}}$ Olivier Muller, MD PhD, ${ }^{a}$ Pier Giorgio Masci, MD PhD, ${ }^{a}$ Stephan Windecker, MD, ${ }^{\mathrm{e}}$ and Juan F. Iglesias, $\mathrm{MD}^{\mathrm{b}}$ Lausanne University Hospital, Geneva, University of Zurich, Bern University Hospital, Lugano, Kantonsspital St. Gallen, and Universita della Svizzera Italiana, Switzerland

Background The benefits of manual thrombus aspiration (TA) during primary percutaneous coronary intervention (pPCI) for ST-elevation myocardial infarction (STEMI) remain uncertain. We assessed the influence of total ischemic time (TIT) on clinical outcomes among STEMI patients undergoing manual TA during $\mathrm{pPCl}$.

Methods and results We conducted a retrospective study of patients enrolled in the Acute Myocardial Infarction in Switzerland Plus registry. STEMI patients undergoing $\mathrm{pPCl}$ with (TA group) or without (PCl-alone group) manual TA were stratified based on short ( $<3$ hours), intermediate (3-6 hours), and long ( $>6$ hours) TIT. The primary endpoint was in-hospital allcause mortality. The secondary endpoint was in-hospital major adverse cardiac events (MACE), a composite of all-cause death, myocardial reinfarction and stroke.

Between 2008 and 2014, 4'154 patients (TA 48\%) were included. Risk-adjusted in-hospital all-cause mortality was not different between TA and PCl-alone groups (OR 1.29;95\% Cl 0.83-1.98; $\mathrm{p}=0.26$ ), whereas there was significantly increased risk of MACE (OR 1.52; $95 \% \mathrm{Cl} 1.05-2.19 ; \mathrm{p}=0.03$ ) in patients treated with manual TA compared with PCl-alone. There was no significant difference between manual TA and PCl-alone with respect to risk-adjusted all-cause mortality according to TIT groups, but risk-adjusted MACE rates were significantly higher in the group of patients with long TIT treated with manual TA compared with PCl-alone (OR 2.42; 95\% Cl 1.16-5.04; $p=0.02$ ).

Conclusion In a large registry of STEMI patients, manual TA was not associated with lower risk-adjusted in-hospital allcause mortality compared with PCl-alone regardless of TIT but was associated with significantly greater risk of MACE. In patients with prolonged TIT, manual TA was associated with higher risk-adjusted MACE rates compared with PCl-alone. (Am Heart J 2018;204:34-42.)

Primary percutaneous coronary intervention (pPCI) is the most effective reperfusion strategy for patients with acute ST-segment elevation myocardial infarction

From the ${ }^{a}$ Department of Cardiology, Lausanne University Hospital, Switzerland, ${ }^{b}$ Division of Cardiology, University Hospital, Geneva, Switzerland, 'AMIS Plus Data Center, University of Zurich, Switzerland, ${ }^{d}$ Department of Cardiology, Triemli Hospital, Zurich, Switzerland, e'Department of Cardiology, Bern University Hospital, Switzerland, 'Department of Cardiology, Cardiocentro Ticino, Lugano, Switzerland, ${ }^{9}$ Division of Cardiology, Kantonsspital St. Gallen, Switzerland, and ${ }^{h}$ Faculty of Biomedical Sciences, Universita della Svizzera Italiana, Switzerland.

Disclosures: The authors have no conflicts of interest to declare.

Submitted November 7, 2017; accepted May 30, 2018.

Reprint requests: Juan F. Iglesias, MD, Division of Cardiology, Geneva University Hospital,

Rue Gabrielle-Perret-Gentil 4, 1211 Geneva 14, Switzerland.

E-mail: JuanFernando.Iglesias@hcuge.ch

$0002-8703$

(c) 2018 Elsevier Inc. All rights reserved.

https://doi.org/10.1016/i.ahi.2018.05.019
(STEMI). ${ }^{1}$ Nonetheless, the success of pPCI for STEMI is currently limited by suboptimal myocardial tissue reperfusion despite achieving epicardial coronary patency, mainly secondary to distal thrombus embolization and microvascular obstruction. Suboptimal coronary reperfusion in patients with STEMI is associated with worse outcomes. ${ }^{2,3}$

Manual thrombus aspiration (TA) during pPCI has been introduced with the intent to reduce thrombus burden, prevent distal embolization and increase microvascular perfusion. However, the clinical benefit of manual TA during pPCI remains uncertain. A single-center randomized trial demonstrated improved myocardial reperfusion and a nearly $50 \%$ reduction in one-year mortality among STEMI patients undergoing manual TA compared with pPCI alone ${ }^{4,5}$ whereas two recent large-scale multicenter randomized trials powered for clinical outcomes ${ }^{6-9}$ and large-scale meta-analysis ${ }^{10}$ have consistently shown that 
routine manual TA during pPCI for STEMI did not reduce all-cause mortality and major adverse cardiovascular events (MACE) during short- and long-term follow-up compared with pPCI alone and might be associated with an increased risk of stroke. Accordingly, current European Society of Cardiology ${ }^{1}$ and American College of Cardiology/American Heart Association guidelines ${ }^{11}$ do not recommend the routine use of manual TA during pPCI for STEMI. However, the question of whether selected patient subgroups may benefit from manual TA during pPCI remains matter of debate due to the lack of robust randomized evidence.

Total ischemic time (TIT), defined as time from symptom onset to reperfusion therapy, is an important independent predictor of myocardial reperfusion, myocardial infarct size, and long-term clinical outcomes in patients undergoing pPCI for STEMI. ${ }^{12-15}$ There is conflicting evidence with regards to the potential interaction between TIT and the effect of manual TA during pPCI. Recent studies have suggested beneficial effects of manual TA over pPCI alone with respect to myocardial reperfusion ${ }^{16}$ and rates of death or MACE ${ }^{17}$ among patient with longer times to treatment. Contrariwise, in a recent large-scale meta-regression analysis, TIT did not influence any potential benefits observed with manual TA. ${ }^{10}$ We aimed to assess the impact of TIT on the clinical benefits of manual TA in a large cohort of STEMI patients undergoing PPCI in contemporary practice.

\section{Methods}

\section{Study design}

We conducted a retrospective analysis of patients included in AMIS (Acute Myocardial Infarction in Switzerland) Plus, a large, nationwide, multicenter registry of patients admitted with acute coronary syndrome (ACS) to hospitals in Switzerland. The design of the registry has been described previously. ${ }^{18}$ Briefly, AMIS Plus prospectively collects 230 items on baseline characteristics, out-of-hospital and early in-hospital management, reperfusion strategy, immediate drug therapy, hospital course, discharge medication and follow-up of patients presenting with ACS in Switzerland. From 106 hospitals treating ACS in Switzerland, 82 hospitals temporarily or continuously enrolled patients in AMIS Plus. Participating centers provide blinded data for each patient through a web-based database and are strongly encouraged to enroll all consecutive patients fulfilling inclusion criteria to avoid selection bias. Hospital data are provided and completed by the treating physician or a trained study nurse. All data are checked for completeness, plausibility and consistency by the AMIS Plus Data Center at the Epidemiology, Biostatistics and Prevention Institute of the University of Zurich, Switzerland.

\section{Study population}

We examined a cohort of STEMI patients included in AMIS Plus who underwent pPCI within 12 hours of symptom onset from January 2008 to December 2014. STEMI was defined by presence of symptoms of ischemia and at least 1-mm (presumed) new persistent ST-segment elevation in $\geq 2$ contiguous limb leads or at least $2-\mathrm{mm}$ in $\geq 2$ contiguous precordial leads, or (presumed) new left bundle branch block. Manual TA was performed at the operator's discretion using one of the approved aspiration devices and was followed by conventional PCI to the culprit lesion. No mechanical aspiration devices were included in this analysis. The choice of antithrombotic therapy was left to the discretion of the treating physician. Epicardial reperfusion was assessed using the Thrombolysis in Myocardial Infarction (TIMI) flow grading system before and after pPCI. TIT was defined as time from symptom onset until pPCI. Patients were divided into two groups based on the use of manual TA before PCI (TA group) or PCI only (PCI-alone group). The TA group included all patients in whom manual TA was attempted. Patients were further stratified into three time groups based on TIT, defined as short ( $<3$ hours), intermediate (between 3 to 6 hours), and long ( $>6$ hours).

\section{Study endpoints}

The primary endpoint was all-cause mortality during the hospital period. The secondary endpoint was MACE, a composite of all-cause death, non-fatal myocardial reinfarction, or stroke, during the hospital period. Non-fatal myocardial reinfarction was defined as presence of recurrent symptoms with concomitant suggestive electrocardiogram (ECG) changes and/or at least two-fold increase in cardiac biomarkers above the upper limit of normal. Stroke was defined as the presence of a new focal neurological deficit thought to be of vascular origin, with signs or symptoms lasting more than 24 hours.

\section{Statistical analysis}

The results are presented as percentages for categorical variables and analyzed using the chi-square test or the Fisher's exact test as appropriate. Continuous normally distributed variables are expressed as means \pm standard deviation (SD) and compared using the two-tailed Student's t-test. Continuous non-normally distributed variables were analyzed using the Mann-Whitney $U$ test and expressed as median and interquartile ranges (IQR). A multivariate logistic regression analysis was performed to account for confounding variables and potential bias between the two treatment groups, including age, gender, diabetes, hypertension, chronic renal failure, multivessel disease, anterior infarction and cardiogenic shock. The results are expressed as odds ratio (OR) and 95\% confidence interval (CI). A p-value of $<0.05$ was considered as statistically significant. SPSS software 
(version 24.0.0, SPSS Inc., Chicago, Illinois, USA) was used for all statistical analyses.

\section{Ethical considerations}

The study protocol complies with the Declaration of Helsinki regarding investigations on humans and was approved the Swiss board for data security and all regional ethics commissions.

\section{Funding}

No extramural funding was used to support this analysis. The authors are solely responsible for the design and conduct of this study, all study analyses, the drafting and editing of the paper and its final contents.

\section{Results}

From $1^{\text {st }}$ January 2008 to $30^{\text {th }}$ April 2014, 18'177 patients with ACS from 51 Swiss hospitals were prospectively enrolled in the AMIS Plus registry. Among 9'715 patients presenting with STEMI during the study period, 8'529 underwent pPCI and the use of manual TA was documented for 5'538 patients. We further excluded 1'384 patients due to missing data on TIT ( $n=1$ '199), peak CK level $(n=89)$ and glycoprotein (GP) IIb/IIIa inhibitors use $(n=96)$. A total of 4 ' 154 patients were included for analysis. Of these, 1'988 (48\%) underwent manual TA during pPCI, whereas 2'166 patients (52\%) were treated with PCI only. The study population was further divided according to the TIT into three subgroups: short TIT $<3$ hours (1'644 patients; TA group, 843 patients; PCIalone group, 801 patients), intermediate TIT between 3 to 6 hours (1'364 patients; TA group, 668 patients; PCIalone group, 696 patients), and long TIT between $>6$ hours (1'146 patients; TA group, 477 patients; PCIalone group, 669 patients) (Figure 1).

\section{Baseline characteristics}

The baseline characteristics of the study population are listed in Table I. Overall, patients in the TA group were younger, more likely male, and had lower rates of hypertension and diabetes mellitus compared with patients in the PCI-alone group. Patients undergoing manual TA had shorter median TIT [200 (IQR 136 to 347) vs. 224 minutes (IQR 146 to 442); $\mathrm{p}<0.001]$ compared with patients undergoing PCI only. The rates of cardiogenic shock and anterior MI were not statistically different between the two groups. Patients in the TA group were less often on aspirin or a $\mathrm{P} 2 \mathrm{Y}_{12}$ receptor antagonist prior to admission compared with patients in the PCI-alone group. There were higher rates of GP IIb/IIIa inhibitors use in the TA group than in the PCI-alone group ( $40.1 \%$ vs. $18.9 \% ; \mathrm{p}<0.001)$. Patients undergoing manual TA were less likely to have multivessel coronary artery disease ( 17.1 vs. $26.9 \%$; $<<0.001)$ and the culprit artery was more frequently located on the left anterior descending artery and right coronary artery compared with patients undergoing pPCI only. Notably, patients in the manual TA group were more likely to have TIMI flow 0 before pPCI $(79.8 \%$ vs. $56.4 \%$; $<<0.001)$ compared with PCI-alone patients. Procedural success rates, defined as rates of post-procedural TIMI flow grade 3 , was not statistically different between manual TA and PCI-alone treated patients $(p=0.57)$. The baseline and procedural characteristics of the study population according to TIT group are summarized in Supplementary Table 1 .

\section{Univariate analysis}

Crude rates of in-hospital all-cause mortality $[3.8 \%$ vs. $3.6 \%$; odds ratio (OR) 1.06 ; $95 \%$ CI 0.77 to $1.47 ; \mathrm{p}=0.71$ ], MACE (5.1\% vs. $4.2 \%$; OR $1.22 ; 95 \%$ CI 0.91 to $1.63 ; \mathrm{p}=$ 0.18 ), stroke (0.6\% vs. $0.3 \%$; OR $1.72 ; 95 \%$ CI 0.66 to 4.43 ; $\mathrm{p}=0.27)$ and cardiogenic shock $(2.7 \%$ vs. $2.8 \%$; OR 0.93 ; $95 \%$ CI 0.64 to $1.37 ; \mathrm{p}=0.72$ ) were not statistically different between TA and PCI-alone groups in the overall patient population (Table II). There was a significantly increased unadjusted risk of myocardial reinfarction (1.0\% vs. $0.4 \%$; OR 2.60; 95\% CI 1.14 to 5.96 ; $=0.02$ ) in patients undergoing manual TA compared with patients in the PCI-alone group (Table II).

In patients with short ( $<3$ hours) and intermediate (3-6 hours) TIT, there were no significant differences between manual TA and PCI alone with respect to crude rates of in-hospital all-cause mortality ( $4.3 \%$ vs. $5.0 \% ; \mathrm{p}=0.56$, and $2.5 \%$ vs. $3.0 \% ; \mathrm{p}=0.63$, respectively) and MACE ( $5.6 \%$ vs. $5.5 \%$; $=0.94$, and $4.0 \%$ vs. $4.2 \%$; $=$ 0.91) (Table III). There was no significant continuous association between TIT and in-hospital all-cause mortality $(p=0.20)$ and MACE $(p=0.30)$. In patients with prolonged TIT ( $>6$ hours), crude rates of all-cause death ( $4.6 \%$ vs. 2.4\%; OR 1.97, p=0.04) and MACE (5.7\% vs. $2.4 \%$; OR $2.17, \mathrm{p}=0.01$ ) were significantly higher with manual TA compared with PCI alone. However, interaction testing between manual TA versus PCI only and TIT groups did not demonstrate significant interaction with respect to all-cause mortality (joint p-value 0.09) and MACE (joint $\mathrm{p}$-value for MACE $\mathrm{p}=0.09$ ).

Among patients in the TA group, there were no significant differences with respect to crude rates of allcause mortality $(4.3 \%, 2.5 \%$, and $4.6 \%$ for TIT $<3,3$ to 6 , and $>6$ hours, respectively, $\mathrm{p}$ for trend $=0.12)$ and MACE $(5.6 \%$, $4 \%, 5.7 \%$ for TIT $<3,3$ to 6 , and $>6$ hours, respectively, $\mathrm{p}$ for trend $=0.32$ ) according to TIT (Table III). Unadjusted inhospital all-cause mortality rates were marginally lower in patients with intermediate TIT (3-6 hours) undergoing manual TA compared with patients with either shorter ( $2.5 \%$ vs. $4.3 \%, \mathrm{p}=0.09)$ or longer $(2.5 \%$ vs. $4.6 \%, \mathrm{p}=0.07)$ times to treatment (Table III). However, there was no significant association between in-hospital all-cause mortality or MACE and continuous TIT in both TA $(p=0.99$ and 


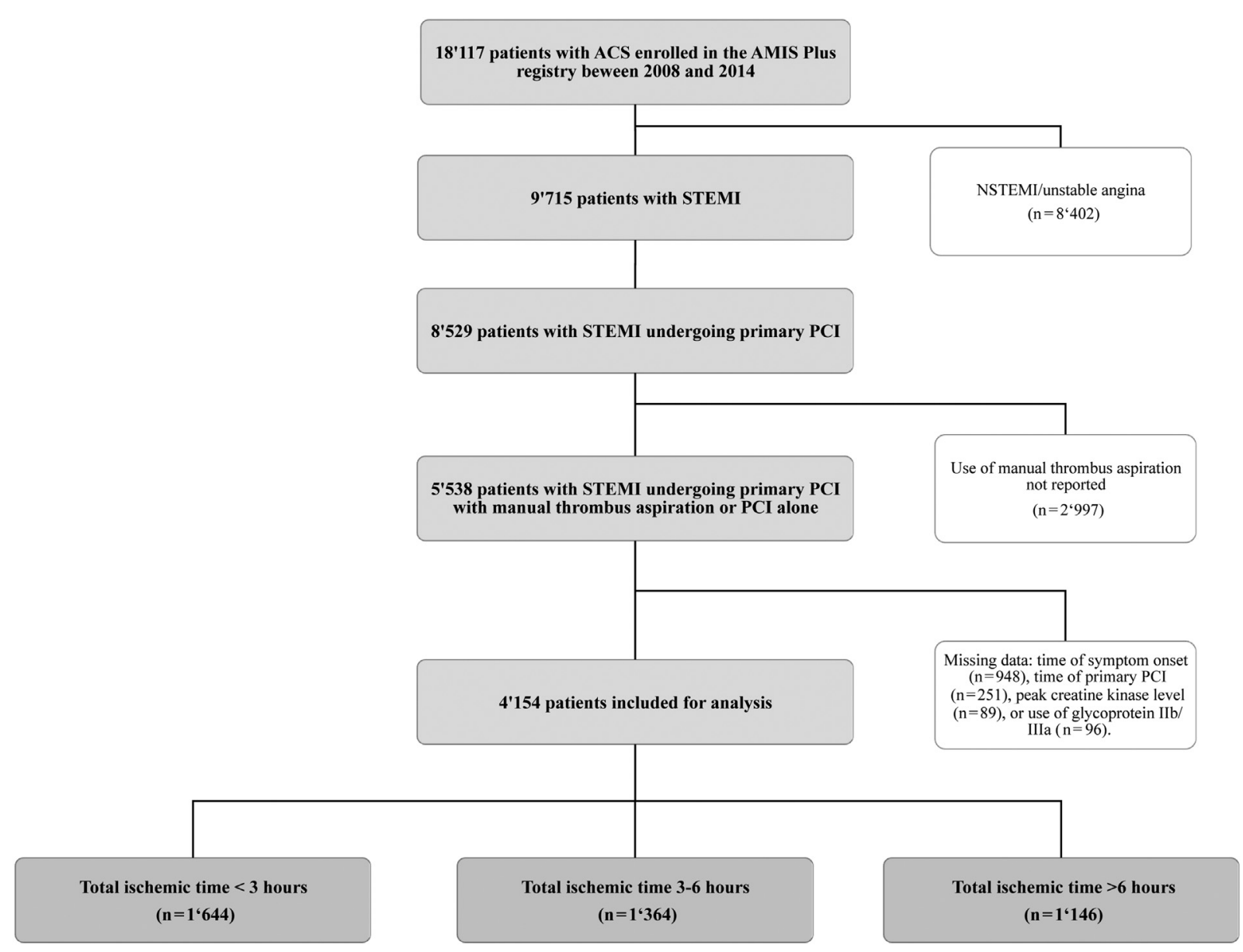

Figure 1

STUDY FLOW CHART ACS: acute coronary syndrome; NSTEMI: non-ST-segment elevation myocardial infarction; PCl: percutaneous coronary intervention; STEMI: ST-segment elevation myocardial infarction; UA: unstable angina.

$\mathrm{p}=0.82$, respectively) and PCI-alone $(\mathrm{p}=0.11$ and $\mathrm{p}=0.32$, respectively).

\section{Multivariate analysis}

Multivariable analysis was performed to account for confounding variables and potential bias between treatment groups. After adjustment for age, gender, diabetes mellitus, hypertension, TIT, chronic renal failure, cardiogenic shock, anterior STEMI, and multivessel disease, inhospital all-cause mortality rates were not significantly different between manual TA and PCI-alone groups (OR 1.29; 95\% CI 0.83-1.98; p=0.26) (Table II, Figure 2), whereas there was a significantly increased adjusted risk of MACE (OR 1.52; 95\% CI 1.05-2.19; p=0.03) among patients treated with manual TA compared with PCI alone (Table IV), driven by an increased risk of myocardial reinfarction (OR 2.45; 95\% CI 1.05-5.76; $\mathrm{p}=$ 0.04) (Table II). There was no significant difference between manual TA and PCI alone with respect to risk- adjusted all-cause mortality according to TIT (Table IV). Compared with PCI-only treated patients, there was a significantly increased adjusted risk of MACE (OR 2.42; 95\% CI 1.16-5.04; $\mathrm{p}=0.02$ ) among patients with prolonged TIT ( $>6$ hours) undergoing manual TA (Table IV). However, no significant interaction between manual TA and TIT groups was found for in-hospital all-cause mortality $(p=0.68)$ and MACE $(p=0.57)$. Increasing age (per additional year, OR 1.05; 95\% CI 1.03-1.07; p<0.001) and cardiogenic shock (OR 25.6; 95\% CI 16.26-40.28; $\mathrm{p}<0.001$ ), but neither manual TA (OR 1.29; 95\% CI 0.83$1.98 ; \mathrm{p}=0.26$ ) nor TIT (TIT 3-6 hours, OR 0.73 ; 95\% CI $0.43-1.25 ; \mathrm{p}=0.25$, and TIT $>6$ hours, OR $1.06 ; 95 \% \mathrm{CI}$ $0.63-1.18 ; \mathrm{p}=0.82$, compared with TIT $<3$ hours, respectively), were independent predictors of in-hospital allcause mortality (Figure 2). Similarly, increasing age (per additional year, OR 1.03; 95\% CI 1.01-1.04; $\mathrm{p}=0.001$ ), anterior myocardial infarction (OR 1.46; 95\% CI 1.012.10; $\mathrm{p}=0.04$ ), cardiogenic shock (OR 17.41; 95\% CI 
Table I. Baseline and procedural characteristics

\begin{tabular}{|c|c|c|c|}
\hline Characteristic & Thrombus aspiration group ( $n=l^{\prime} 988$ ) & PCl-alone group ( $n=2$ '166) & $\mathrm{p}$ value \\
\hline Age (years) & $61 \pm 12.4$ & $63.9 \pm 12.7$ & $<0.001$ \\
\hline Male gender & $1582(79.6)$ & $1614(74.5)$ & $<0.001$ \\
\hline Body mass index $\left(\mathrm{kg} / \mathrm{m}^{2}\right)$ & $27 \pm 4.3$ & $27 \pm 4.5$ & 0.98 \\
\hline Hypertension & $977 / 1905$ (51.3) & $1170 / 2042$ (57.3) & $<0.001$ \\
\hline Dyslipidemia & $1019 / 1818(56.1)$ & $1052 / 1916$ (54.9) & 0.48 \\
\hline Diabetes mellitus & $266 / 1946$ (13.7) & $338 / 2062(16.4)$ & 0.002 \\
\hline Smoking status & & & 0.29 \\
\hline Never & $551 / 1848(29.8)$ & $615 / 1915(32.1)$ & \\
\hline Former & $433 / 1848(23.4)$ & $443 / 1915(23.1)$ & \\
\hline Current & $864 / 1848(46.8)$ & $857 / 1915(44.8)$ & \\
\hline Total ischemic time, min (median/IQR) & $200(136 ; 347)$ & $224(146 ; 442)$ & $<0.001$ \\
\hline Previous myocardial infarction & $202 / 1950(10.4)$ & $263 / 2098(12.5)$ & 0.03 \\
\hline Heart failure & $18 / 1765(1.0)$ & $37 / 2066(1.8)$ & 0.06 \\
\hline Renal disease & $60 / 1946(3.1)$ & $86 / 2088(4.1)$ & 0.09 \\
\hline Cerebrovascular disease & $71 / 1946$ (3.6) & $83 / 2088(4.0)$ & 0.62 \\
\hline Previous $\mathrm{PCl}$ & $235 / 1950(12.1)$ & $255 / 2098(12.2)$ & 0.92 \\
\hline Previous CABG & $36 / 1950(1.8)$ & $64 / 2098(3.1)$ & 0.01 \\
\hline Killip class 4 & $111 / 1974(5.6)$ & $112 / 2159(5.2)$ & 0.76 \\
\hline Killip class $>2$ & $143 / 1974(7.2)$ & $152 / 2159(7.0)$ & 0.81 \\
\hline Anterior myocardial infarction & $814 / 1984(41)$ & $939 / 2162(43.4)$ & 0.12 \\
\hline \multicolumn{4}{|l|}{ Medical treatment prior to admission } \\
\hline Aspirin & $395 / 1794(22.0)$ & $515 / 1930(26.7)$ & 0.001 \\
\hline $\mathrm{P} 2 \mathrm{Y}_{12}$ antagonist & $113 / 1988(5.7)$ & $172 / 2166(7.9)$ & 0.004 \\
\hline Oral anticoagulation & $55 / 1786(3.1)$ & $67 / 906(3.5)$ & 0.46 \\
\hline \multicolumn{4}{|l|}{ Medical treatment during admission } \\
\hline Aspirin & 1944/1983 (98.0) & $2130 / 2166$ (98.3) & 0.46 \\
\hline$P 2 Y_{12}$ antagonist & 1909/1988 (96.0) & $2112 / 2166$ (97.5) & 0.007 \\
\hline Glycoprotein Ilb/Illa antagonist & $797 / 1988(40.1)$ & $409 / 2166$ (18.9) & $<0.001$ \\
\hline Anticoagulation & 1848/1988 (93) & 1943/2166 (89.7) & $<0.001$ \\
\hline Thrombolysis & $7 / 1988(0.4)$ & $6 / 2166(0.3)$ & 0.67 \\
\hline \multicolumn{4}{|l|}{ Number of diseased vessels } \\
\hline 1 & $1000 / 1988$ (50.3) & $902 / 2166(41.6)$ & $<0.001$ \\
\hline 2 & $569 / 1988(28.6)$ & $666 / 2166(30.7)$ & 0.13 \\
\hline 3 & $339 / 1988(17.1)$ & $582 / 2166(26.9)$ & $<0.001$ \\
\hline Infarct-related artery & & & 0.005 \\
\hline Left main coronary artery & $9 / 1358(0.7)$ & $20 / 1228(1.6)$ & \\
\hline Left anterior descending artery & $575 / 1358(42.3)$ & $538 / 1228(43.8)$ & \\
\hline Right coronary artery & $588 / 1358(43.3)$ & $464 / 1228(37.8)$ & \\
\hline Left circumflex artery & $171 / 1358(12.6)$ & $187 / 1228(15.2)$ & \\
\hline TIMI flow grade before PCI & & & $<0.001$ \\
\hline 0 & $1125 / 1410$ (79.8) & $795 / 1410(56.4)$ & \\
\hline 1 & $93 / 1410(6.6)$ & $193 / 1410(13.7)$ & \\
\hline 2 & $90 / 1410(6.4)$ & 184/1410 (13) & \\
\hline 3 & $102 / 1410(7.2)$ & $238 / 1410(16.9)$ & \\
\hline TIMI flow grade after PCI & & & 0.008 \\
\hline 0 & $8 / 1749(0.5)$ & 24/1719 (1.4) & \\
\hline 1 & $19 / 1749(1.1)$ & $12 / 1719(0.7)$ & \\
\hline 2 & $85 / 1749(4.9)$ & $66 / 1719(3.8)$ & \\
\hline 3 & $1637 / 1749$ (93.6) & $1617 / 1719(94.1)$ & \\
\hline
\end{tabular}

Data are mean $( \pm S D)$ or number of patients $(\%)$. IQR: interquartile range.

$C A B G$, Coronary artery bypass graft; $P C l$, percutaneous coronary intervention; TIMI, Thrombolysis in Myocardial Infarction.

11.65-26.01; $\mathrm{p}<0.001)$ and manual TA (OR 1.52; 95\% CI 1.05-2.20; $\mathrm{p}=0.03$ ), but not TIT (TIT 3-6 hours, OR 1.00; 95\% CI 0.65-1.55; $\mathrm{p}=0.99$, and TIT $>6$ hours, OR 1.02; 95\% CI $0.65-1.61 ; \mathrm{p}=0.93$, compared with TIT $<3$ hours, respectively), were independent predictors of in-hospital MACE.

When adding TIMI flow grade 0 before pPCI to the multivariate model ( $n=2 ' 359$ patients), there was no significant difference between manual TA and PCI alone with respect to risk-adjusted all-cause mortality (OR 1.40; 95\% CI 0.76-2.40; p=0.30) (Supplementary Table 2). Increasing age (per additional year, OR 1.04; 95\% CI 1.011.07; $\mathrm{p}=0.002$ ), diabetes mellitus (OR 2.27; 95\% CI 1.22$4.21 ; \mathrm{p}=0.01$ ), anterior myocardial infarction (OR 1.99; 95\% CI 1.14-3.49; $\mathrm{p}=0.02)$ and cardiogenic shock (OR 24.42; 95\% CI 13.51-44.16; $<<0.001$ ), but neither TIMI 
Table II. In-hospital clinical outcomes

UNIVARIATE ANALYSIS

\begin{tabular}{|c|c|c|c|c|c|c|c|c|}
\hline OUTCOMES & Thrombus aspiration group & $\mathrm{PCl}$-alone group & Unadjusted OR & $95 \% \mathrm{Cl}$ & $p$ value & $\begin{array}{c}\text { Adjusted } \\
\text { OR }\end{array}$ & $95 \% \mathrm{Cl}$ & $p$ value \\
\hline All-cause mortality & $75 / 1988$ (3.8) & $77 / 2166(3.6)$ & 1.06 & $0.77-1.47$ & 0.71 & 1.29 & $0.83-1.98$ & 0.26 \\
\hline MACE & $101 / 1988(5.1)$ & $91 / 2166(4.2)$ & 1.22 & $0.91-1.63$ & 0.18 & 1.52 & $1.05-2.19$ & 0.03 \\
\hline Myocardial reinfarction & $19 / 1987(1.0)$ & $8 / 2166(0.4)$ & 2.60 & $1.14-5.96$ & 0.02 & 2.45 & $1.05-5.76$ & 0.04 \\
\hline Stroke & $11 / 1987(0.6)$ & $7 / 2166(0.3)$ & 1.72 & $0.66-4.44$ & 0.27 & 2.14 & $0.76-6.01$ & 0.15 \\
\hline Cardiogenic shock & $48 / 1806$ (2.7) & $61 / 2144(2.8)$ & 0.93 & $0.64-1.37$ & 0.72 & 1.11 & $0.72-1.72$ & 0.64 \\
\hline
\end{tabular}

Data are number of patients (\%). Cl: confidence interval, OR: odds ratio.

MACE, Major adverse cardiovascular events, composite of all-cause mortality, myocardial reinfarction, or stroke; $P C l$, percutaneous coronary intervention.

Table III. In-hospital clinical outcomes according to total ischemic time

ALL-CAUSE MORTALITY

Total

ischemic

time

$<3$ hours $76 / 1644 \quad 36 / 843$

$\begin{array}{ccc} & (4.6) & (4.3) \\ 3-6 & 38 / 1364 & 17 / 668 \\ \text { hours } & (2.8) & (2.5)\end{array}$

(3.3) (4.6)

$>6$ hours $38 / 1146 \quad 22 / 477$

Data are number of patients (\%). Cl: confidence interval, OR: odds ratio.

MACE, Major adverse cardiovascular events; $P C l$, percutaneous coronary intervention; TA, thrombus aspiration. flow grade 0 before pPCI (OR 0.59; 95\% CI 0.29-1.20; $\mathrm{p}=0.15$ ) nor TIT (TIT 3-6 hours, OR 0.66 ; 95\% CI 0.33 $1.31 ; \mathrm{p}=0.23$, and TIT $>6$ hours, OR $1.05 ; 95 \%$ CI $0.54-$ 2.06; $\mathrm{p}=0.88$, compared with TIT $<3$ hours, respective1y), were independent predictors of in-hospital all-cause mortality (Supplementary Table 2).

\section{Discussion}

The major findings of the present study can be summarized as follows: (1) manual TA during pPCI did not reduce risk-adjusted in-hospital all-cause mortality rates compared with PCI alone irrespective of TIT; (2) manual TA during pPCI was associated with a significantly increased adjusted risk of MACE compared with PCI alone; and (3) manual TA in patients with prolonged TIT was associated with significantly increased risk-adjusted in-hospital MACE rates compared with PCI alone. To the best of our knowledge, this is the largest study evaluating the influence of TIT on the clinical benefit of manual TA during pPCI.

In our large registry of STEMI patients undergoing pPCI, routine manual TA did not reduce the risk of in-hospital all-cause death, MACE, and cardiogenic shock when compared with PCI alone, whereas there was a trend towards an increased risk of stroke. These findings are consistent with the results of two recent large-scale randomized clinical trials ${ }^{6-9}$ and subsequent metaanalyses ${ }^{10,20}$ demonstrating that routine manual TA during PCI for STEMI does not improve clinical outcomes at the expense of an increased risk of stroke, whereas there was a trend towards reduced cardiovascular death in the subgroup of patients with high thrombus burden. ${ }^{10}$ However, current evidence is mainly limited to patients presenting within the first hours after symptom onset ${ }^{6-9}$ and the impact of TIT on manual TA efficacy in the contemporary pPCI era is currently uncertain, owing to the contradictory results of previous studies. ${ }^{10,14,16,17,19,23-27}$

Prolonged TIT in the setting of STEMI has been associated with suboptimal myocardial reperfusion, larger infarct size and increased 1-year mortality rates. ${ }^{12-15,21}$ Patients presenting late after symptom onset display particularly high thrombus burden owing to long ischemic times, but data on manual TA efficacy in the subgroup of patients with STEMI presenting late after symptom onset are scarce and matter of debate. Prior small-sized randomized studies ${ }^{16,24}$ and post-hoc meta-regression analysis of early randomized trials ${ }^{17}$ suggested that manual TA may indeed be more effective in the subgroup of late-presenting patients undergoing pPCI. In the VAcuuM asPIration thrombus REmoval (VAMPIRE) study, manual TA was 


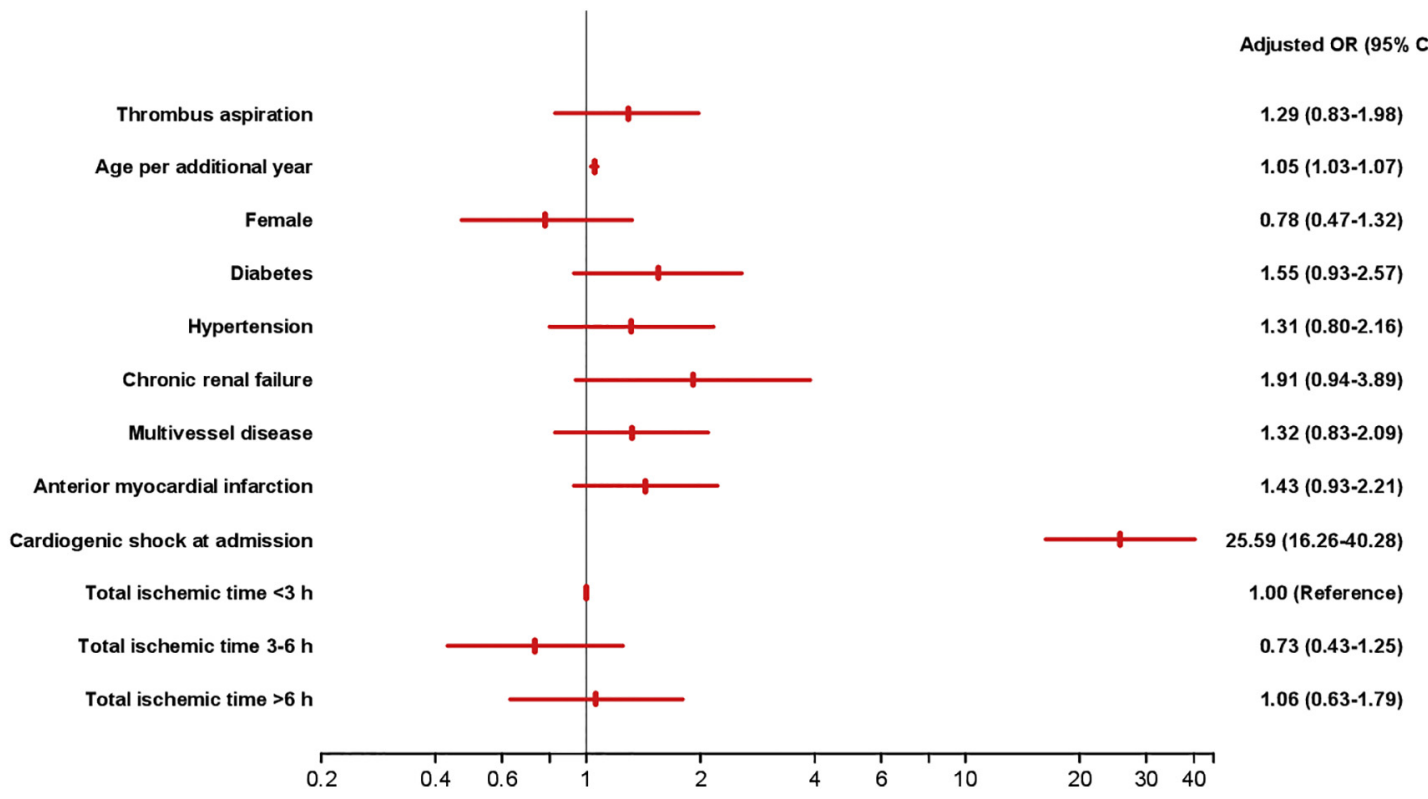

Figure 2

RISK-ADJUSTED IN-HOSPITAL ALL-CAUSE MORTALITY. Predictors of in-hospital all-cause mortality after adjustment for age, gender, cardiovascular risk factors, TIT, multivessel disease, and chronic renal failure.Cl: confidence interval; OR: odds ratio; TIT: total ischemic time.

Table IV. Risk-adjusted in-hospital clinical outcomes in patients undergoing manual thrombus aspiration according to total ischemic time

\begin{tabular}{|c|c|c|c|c|c|c|}
\hline \multirow{2}{*}{$\begin{array}{l}\text { Total } \\
\text { ischemic } \\
\text { time }\end{array}$} & \multicolumn{3}{|c|}{ ALL-CAUSE MORTALITY } & \multicolumn{3}{|c|}{ MACE } \\
\hline & Risk-adjusted OR & $95 \% \mathrm{Cl}$ & $p$ value & Risk-adjusted OR & $95 \% \mathrm{Cl}$ & $p$ value \\
\hline Overall & 1.29 & $0.83-1.98$ & 0.26 & 1.52 & $1.05-2.19$ & 0.03 \\
\hline$<3$ hours & 1.25 & $0.64-2.45$ & 0.51 & 1.59 & $0.88-2.88$ & 0.13 \\
\hline 3-6 hours & 0.88 & $0.38-2.04$ & 0.77 & 1.08 & $0.58-2.04$ & 0.81 \\
\hline$>6$ hours & 1.93 & $0.85-4.37$ & 0.12 & 2.42 & $1.16-5.04$ & 0.02 \\
\hline
\end{tabular}

Cl, Confidence interval; MACE, major adverse cardiovascular events; OR, odds ratio.

shown to significantly improve myocardial reperfusion and reduce adverse ischemic events compared with PCI-alone when performed among patients presenting between 6 and 24 hours after symptom onset compared to patients treated with early ( $<6$ hours) reperfusion. ${ }^{24}$ However, in the largest cohort of late-presenting STEMI patients undergoing cardiac magnetic resonance imaging for the assessment of myocardial reperfusion, manual TA did not reduce the extent of microvascular obstruction and clinical outcomes compared with PCI alone as the result of only a moderate amount of salvageable myocardium at later stages. ${ }^{26}$ Our results demonstrate no significant association with respect to risk-adjusted all-cause mortality between manual TA and PCI alone, whereas manual TA was associated with a significantly increased adjusted risk of MACE compared with pPCI alone, mainly driven by an increased risk of myocardial reinfarction. These findings suggest that manual TA may not be appropriate for patients with prolonged TIT and add new insights on the crucial issue of the appropriate selection of STEMI patient subsets that might derive benefit from the selective use of manual TA during pPCI.

The results of the present analysis are consistent with several previous large studies. ${ }^{4-10,19,23}$ No influence of TIT on manual TA efficacy was observed in the singlecenter Thrombus Aspiration During Percutaneous Coronary Intervention in Acute Myocardial Infarction Study (TAPAS) ${ }^{4,5}$ and the large multicenter Thrombus Aspiration in ST-Elevation Myocardial Infarction in Scandinavia (TASTE) ${ }^{6,7}$ and Trial of Routine Aspiration Thrombectomy With PCI Versus PCI Alone (TOTAL) ${ }^{8,9}$ randomized trials. Individual patient-level meta-analysis of 
these trials did not demonstrate significant differences with respect to cardiovascular death at 30 days between manual TA and PCI-only in patients with TIT $>6$ hours and between 6 and 12 hours, whereas numerically higher cardiovascular mortality rates were found among patients with prolonged ( $>12$ hours) times from symptom onset in the manual TA group compared with PCI-alone treated patients. ${ }^{19}$ Furthermore, meta-regression analysis of a large meta-analysis did not identify any potential benefits of manual TA with respect to all-cause death based on TIT. ${ }^{10}$ However, at variance from the results of our large contemporary STEMI cohort, the study did not demonstrate significant differences with respect to MACE based on TIT. $^{10}$

The mechanistic insights underlying the influence of TIT on clinical outcomes following manual TA cannot be directly derived from our study. However, intracoronary thrombus formation in STEMI patients is a dynamic process and thrombus composition may play an important role. Whereas thrombotic material is relatively soft at initial stages (low fibrin content, high platelet content), thrombus becomes more organized over time (high fibrin content, low platelet content). Thus, thrombus is possibly less suited for manual TA and more likely to disrupt resulting in significant iatrogenic distal embolization at later stages, ${ }^{21}$ where additionally there is no, or only minimal, residual myocardium to be salvaged. ${ }^{26}$ Finally, as observed in the current analysis, patients undergoing manual TA are substantially younger, with one-vessel disease and without prior myocardial infarction compared with patients treated with PCI-alone. This lower atherosclerotic burden might result in reduced tolerance to acute myocardial ischemia and increased susceptibility to worse clinical outcomes among patients undergoing manual TA.

Our data must be interpreted in view of several limitations. First, our study includes all limitations of a large nationwide registry, such as potential bias and unmeasured confounders associated with nonrandomized studies. Highest-risk patients may not have been considered for an invasive management and we cannot exclude the possibility of underreporting of clinical outcomes. In addition, the potential effect of confounding by indication on MACE rates cannot be formally excluded. The use of manual TA was left at the discretion of the operator and a potential selection bias with inclusion of lesions with higher thrombus burden in the TA group cannot be excluded. Despite the large size of our study population, our cohort may not have the power to detect differences in rates of in-hospital all-cause mortality related to the use of manual TA among subgroups of STEMI patients. All-cause mortality rates reported in our large contemporary cohort of STEMI patients treated with pPCI were low, suggesting a potential quantitative interaction, thus underestimating the treatment benefit in this 'low-risk' patient population.
Finally, thrombus grade and findings on the results of manual TA such as no retrieval of debris or failure of the catheter to cross the culprit lesion were not recorded.

\section{Conclusion}

In a large cohort of patients with STEMI undergoing pPCI, manual TA was not associated with lower riskadjusted in-hospital all-cause mortality compared with PCI-alone regardless of TIT but was associated with significantly greater risk of MACE. In patients with prolonged TIT, manual TA was associated with higher risk-adjusted MACE rates compared with PCI-alone. These results warrant confirmation by further analyses from existing randomized clinical trials.

\section{Appendix A. Supplementary data}

Supplementary data to this article can be found online at https://doi.org/10.1016/j.ahj.2018.05.019.

\section{References}

1. Ibanez B, James S, Agewall S, et al. 2017 ESC Guidelines for the management of acute myocardial infarction in patients presenting with ST-segment elevation: The Task Force for the management of acute myocardial infarction in patients presenting with ST-elevation of the European Society of Cardiology (ESC). Eur Heart J 2018;39(2): 119-77.

2. Van't Hof AW, Liem A, Suryapranata H, et al. Angiographic assessment of myocardial reperfusion in patients treated with primary angioplasty for acute myocardial infarction: myocardial blush grade. Zwolle Myocardial Infarction Study Group. Circulation 1998;97: 2302-6.

3. Van't Hof AW, Liem A, de Boer MJ, et al. Clinical value of 12-lead electrocardiogram after successful reperfusion therapy for acute myocardial infarction. Zwolle Myocardial infarction Study Group. Lancet 1997;350:615-9.

4. Svilaas T, Vlaar PF, van der Horst IC, et al. Thrombus aspiration during primary percutaneous coronary intervention. N Engl J Med 2008;358:557-67.

5. Vlaar PF, Svilaas T, van der Horst IC, et al. Cardiac death and reinfarction after 1 year in the Thrombus Aspiration during Percutaneous coronary intervention in Acute myocardial infarction study (TAPAS). A 1-year follow-up study. Lancet 2008;371:1915-20.

6. Fröbert O, Lagerqvist B, Olivecrona GK, et al. Thrombus Aspiration in ST-Elevation Myocardial Infarction (TASTE trial). N Engl J Med 2013;369:1587-97.

7. Lagerqvist B, Fröbert O, Olivecrona GK, et al. Outcomes 1 Year after Thrombus Aspiration for Myocardial Infarction. N Engl J Med 2014;371:1111-20.

8. Jolly SS, James $S$, Džavík $V$, et al. Randomized trial of primary PCI with or without routine manual thrombectomy. $N$ Engl J Med 2015;372(15):1389-98.

9. Jolly SS, Cairns JA, Yusuf S, et al. Outcomes after thrombus aspiration for ST elevation myocardial infarction: 1-year follow-up of the 
prospective randomized TOTAL trial. Lancet 2016;387(10014): 127-35.

10. Elgendy IY, Huo T, Bhatt DL, et al. Is Aspiration Thrombectomy Beneficial in Patients Undergoing Primary Percutaneous Coronary Intervention? Meta-Analysis of Randomized Trials. Circ Cardiovasc Interv 2015;8, e002258.

11. Levine GN, Bates ER, Blankenship JC, et al. 2015 ACC/AHA/SCAI Focused Update on Primary Percutaneous Coronary Intervention for Patients With ST-Elevation Myocardial Infarction: An Update of the 2011 ACCF/AHA/SCAI Guideline for Percutaneous Coronary Intervention and the 2013 ACCF/AHA Guideline for the Management of ST-Elevation Myocardial Infarction. J Am Coll Cardiol 2016;67(10):1235-50.

12. De Luca G, van 't Hof AW, de Boer MJ, et al. Time-to-treatment significantly affects the extent of ST-segment resolution and myocardial blush in patients with acute myocardial infarction treated by primary angioplasty. Eur Heart J 2004;25(12):1009-13.

13. De Luca G, Suryapranata H, Ottervanger JP, et al. Time delay to treatment and mortality in primary angioplasty for acute myocardial infarction: every minute of delay counts. Circulation 2004;109(10): 1223-5.

14. Balan $P$, Anderson HV. Aspiration thrombectomy: it's about time. J Am Coll Cardiol 2013;62:1419-20.

15. Denktas AE, Anderson HV, McCarthy J, et al. Total ischemic time: the correct focus of attention for optimal ST-segment elevation myocardial infarction care. JACC Cardiovasc Interv 2011;4:599-604.

16. De Vita M, Burzotta F, Porto I, et al. Thrombus aspiration in ST elevation myocardial infarction: comparative efficacy in patients treated early and late after onset of symptoms. Heart 2010;96(16): 1287-90.

17. De Rosa S, Caiazzo G, Torella D, et al. Aspiration thrombectomy: an easily forgiven "latecomer" (letter). J Am Coll Cardiol 2014;63(19):2052-3.
18. Radovanovic D, Erne P. AMIS Plus: Swiss registry of acute coronary syndrome. Heart 2010;96:917-21.

19. Jolly SS, James S, Džavík V, et al. Thrombus Aspiration in STSegment-Elevation Myocardial Infarction: An Individual Patient MetaAnalysis: Thrombectomy Trialists Collaboration. Circulation 2017;135(2): 143-52

20. Wieringa WG, van der Horst IC, Boersma E, et al. Quantitative analysis of the impact of total ischemic time on myocardial perfusion and clinical outcome in patients with ST-elevation myocardial infarction. Am J Cardiol $2011 ; 108(11): 1536-41$.

21. Silvain J, Collet JP, Nagaswami C, et al. Composition of coronary thrombus in acute myocardial infarction. J Am Coll Cardiol 2011;57 (12):1359-67.

22. Noman A, Egred M, Bagnall A, et al. Impact of thrombus aspiration during primary percutaneous coronary intervention on mortality in ST-segment elevation myocardial infarction. Eur Heart J 2012;33:3054-61.

23. Ikari Y, Sakurada M, Kozuma K. Upfront thrombus aspiration in primary coronary intervention for patients with ST-segment elevation acute myocardial infarction: report of the VAMPIRE (VAcuuM asPlration thrombus REmoval) trial. JACC Cardiovasc Interv 2008;1(4):424-31.

24. Chao CL, Hung CS, Lin YH, et al. Time-dependent benefit of initial thrombosuction on myocardial reperfusion in primary percutaneous coronary intervention. Int J Clin Pract 2008;62(4):555-61.

25. Desch S, Stiermaier Th, De Waha S, et al. Thrombus Aspiration in Patient with ST-Segment Myocardial Infarction Presenting Late After Symptom Onset. JACC Cardiovasc Interv 2016;9(2):113-22.

26. Kumbhani DJ, Bavry AA, Desai MY, et al. Role of aspiration and mechanical thrombectomy in patients with acute myocardial infarction undergoing primary angioplasty: an updated meta-analysis of randomized trials. J Am Coll Cardiol 2013;62(16):1409-18. 